\title{
Correlations Between Range of Motion and Elasticity of the Coracohumeral Ligament Evaluated With Shear-Wave Elastography
}

\author{
Kenji Kanazawa, Yoshihiro Hagiwara, Takuya Sekiguchi, Ryo Fujita, Kazuaki Suzuki, Masashi Koide, \\ Akira Ando, and Yutaka Yabe
}

\begin{abstract}
Context: Range of motion (ROM) in the glenohumeral joint decreases with age in healthy subjects; however, the underlying mechanism remains unclear. The process of aging of the joint capsule, including the coracohumeral ligament (CHL), could affect ROM limitation. Objective: This study investigated correlations between elasticity of the CHL, evaluated by means of shearwave elastography, and age, side dominance, and ROM in healthy individuals. Design: Experimental study. Setting: Laboratory. Subjects: Eighty-four healthy volunteers (39 men and 45 women, mean age: 42.6 y) were included. Main Outcome Measures: Subjects were divided into 3 age groups: younger (20-39y), middle ( $40-59 \mathrm{y}$ ), and older ( $\geq 60 \mathrm{y})$ age groups. With participants in the supine position, CHL elasticity in both shoulders was evaluated in both neutral and $30^{\circ}$ external rotation, with arms at the sides. ROM, including forward flexion, lateral elevation, external rotation, $90^{\circ}$ abduction with external rotation, and hand behind the back were measured with participants in the standing position. Results: The CHL elastic modulus was higher in the older group than in the younger group in the neutral (78.4 $\mathrm{kPa}$ [SD: 37.1 ] and $56.6 \mathrm{kPa}$ [SD: 31.7], respectively) and $30^{\circ}$ external rotation positions (135.5 $\mathrm{kPa}$ [SD: 63.5$]$ and $71.4 \mathrm{kPa}$ [SD: 32.2], respectively). Negative correlations were found between the CHL elastic modulus and ROM in terms of $30^{\circ}$ external rotation and both external rotation $(R=-.59, P=.02)$ and $90^{\circ}$ abduction with external rotation $(R=-.71, P=.003)$ in the older group, with correlation coefficients increasing with age. Conclusions: Significant correlations were identified between CHL elasticity and ROM in both external rotation and $90^{\circ}$ abduction with external rotation with increasing age. Decreased CHL elasticity was strongly associated with decreased shoulder ROM in middleaged and older individuals.
\end{abstract}

Keywords: frozen shoulder, restriction, elastic modulus, ultrasonography, shoulder dominance

Shoulder motion is a combined motion of the glenohumeral, scapulothoracic, acromioclavicular, and sternoclavicular joints, ${ }^{1,2}$ as well as posture, including thoracic kyphosis. ${ }^{3}$ Restriction of the range of motion (ROM) of the shoulder joint has detrimental effects on the activities of daily living. Severely restricted ROM in all planes is a feature of frozen shoulder. A thickened joint capsule, including the coracohumeral ligament (CHL), at the rotator interval has been recognized to be one of the most specific manifestations of frozen shoulder. The CHL covers the rotator interval, as well as the entire supraspinatus and subscapularis muscles and is anchored to the coracoid process, functioning as a support structure for both the supraspinatus and subscapularis muscles. ${ }^{4-6}$ Therefore, a stiffened CHL restricts the sliding motion of the supraspinatus and subscapularis muscles around the base of the coracoid process. The thickening of the CHL is correlated with external rotation restriction,, 78 as well as internal rotation restriction of the glenohumeral joint in frozen shoulder. ${ }^{9}$ A recent study showed that arthroscopic pancapsular release, including that of the CHL, is an effective surgical procedure for regaining full ROM in frozen shoulder. ${ }^{10}$ In addition, $\mathrm{CHL}$ release is a selective procedure for preventing postoperative

Kanazawa is with the Department of Orthopaedic Surgery, South Miyagi Medical Center, Ogawara, Japan. Hagiwara and Yabe are with the Department of Orthopaedic Surgery, Tohoku University School of Medicine, Sendai, Japan. Sekiguchi and Fujita are with the Department of Orthopaedic Surgery, Iwate Prefectural Central Hospital, Morioka, Japan. Suzuki is with the Department of Orthopaedic Surgery, JR Sendai Hospital, Sendai, Japan. Koide and Ando are with the Department of Orthopaedic Surgery, Matsuda Hospital, Sendai, Japan. Hagiwara (hagi@med. tohoku.ac.jp) is corresponding author. stiffness in patients with rotator cuff tear. ${ }^{11}$ These findings suggest that the CHL also affects ROM restriction in some shoulder diseases.

Although capsular thickening is one of the main factors in ROM restriction in pathological conditions in the shoulder, ROM in the glenohumeral joint also decreases with age in healthy subjects. ${ }^{12,13}$ With natural aging of the joint capsule, limitation in ROM occurs due to the age-related reduction of oxygenated blood flow. Blood flow is a key to understanding pathologies of the joint capsule,$^{14,15}$ which has multiple contributing factors, such as inflammation, fibrosis, and chondrogenesis in the pathogenesis of frozen shoulder. ${ }^{16}$ The CHL may be deeply involved in the pathogenesis of shoulder degenerative disorders. In addition, while the CHL is thought to influence multidirectional ROM restrictions in shoulder diseases, it is not entirely clear whether stiffness of the CHL varies with age and is related to ROM in the general population. Further research on this topic could elucidate the cause and effects of restriction in shoulder ROM.

Shear-wave elastography is a technique that was developed to analyze tissue quality, with a focus on elasticity. ${ }^{17}$ Shear-wave elastography provides noninvasive quantitative and local elastic information on soft tissues in real time, based on viscoelastic properties. ${ }^{17}$ The system generates and propagates shear waves into tissues and assesses their elastic modulus ${ }^{18}$ and has been applied to the Achilles ${ }^{19}$ and rotator cuff tendons..$^{20}$ Furthermore, it has been used for measuring elasticity of the CHL in frozen shoulder and has demonstrated that the CHL on the affected side was often markedly stiffer than that on the unaffected side. ${ }^{21}$ Because the CHL is in the superficial layer, compared with the other part of the joint capsule, it can be easily evaluated by shear-wave elastography and could be used as an index of age-related change. 
The purpose of this study was to investigate correlations between ROM and CHL elasticity, by using shear-wave elastography evaluation, in order to verify and expand upon data suggesting that $\mathrm{CHL}$ elasticity decreases with age and influences ROM restrictions.

\section{Materials and Methods}

\section{Subjects}

A total of 84 volunteers ( 39 men and 45 women) who worked in our institution were recruited and participated in this study. None of the study participants had a history of shoulder girdle trauma, frozen shoulder, instability, or arthritis. Rotator cuff tears were evaluated with ultrasonography. The mean age was 42.6 years (range: 22-69 y, SD: $13.6 \mathrm{y}$ ). The patients were divided into 3 groups according to age: younger $(20-39 \mathrm{y}, \mathrm{n}=36)$, middle $(40-59 \mathrm{y}$, $n=33)$, and older ( $\geq 60 y, n=15)$ age groups. Exclusion criteria were a history of fractures around the shoulder girdle, previous shoulder and chest operations, rotator cuff abnormalities confirmed by ultrasound performed by an experienced orthopedic surgeon, and systemic metabolic diseases, including diabetes mellitus.

\section{Procedures}

Before the shear-wave elastography examination, 2 experienced physiotherapists, with over 8 and 10 years of experience in musculoskeletal therapy, evaluated the ROM measurements, including forward flexion, lateral elevation, external rotation, and $90^{\circ}$ abduction with external rotation, using a goniometer, with patients in a standing position. Hand behind the back motion was measured by asking the patients to place the thumb on the highest possible spinal vertebrae, in the same position. The 2 examiners consistently performed all measurements with 1 examiner positioned at the extremity and the other aligned to read the goniometer.

\section{Ultrasonography Evaluation}

Bilateral shoulder evaluation was performed in neutral and $30^{\circ}$ external rotation positions using shear-wave elastography (Supersonic Imagine, Aix-En-Provence, France) equipped with a 4- to 15$\mathrm{MHz}$ superficial linear probe. We chose external rotation with an angle of $30^{\circ}$ because it is about half of the normal range of external rotation.

\section{Measuring Elasticity of the $\mathrm{CHL}$}

Two experienced orthopedic surgeons with more than 11 and 13 years of musculoskeletal ultrasonographic evaluation, who had no access to participant information, measured the elasticity of the CHL, independently. Participants remained in a supine position on an examination table to facilitate accurate measurement. The assistant physiotherapists maintained the elbow at $90^{\circ}$ flexion, with the arm at the side, and sequentially changed the elbow position from the neutral to $30^{\circ}$ external rotation. B-mode ultrasound was performed in an axial oblique plane by placing the transducer on the lateral portion of the coracoid process, which revealed a longitudinal image of the $\mathrm{CHL}$ on the surface of the subscapularis. ${ }^{21}$ The posture of participants and the transducer position were the same in the B-mode ultrasound evaluation as for shear-wave elastography examination.
The tip of the transducer was covered with a gel and was placed smoothly on the skin without placing pressure on the tissue. Given that motion of the chest wall could interfere with elastogram stability, participants were asked to hold their breath for 5 to 10 seconds during measurements. Elasticity of the CHL at the surface of the subscapularis was measured and recorded at both the centermost point of the coracoid process and the primary attachment point of the subscapularis in both the neutral (Figure 1A) and $30^{\circ}$ external rotation positions (Figure 1C). A region of interest with a diameter of $1.5 \mathrm{~mm}$ was set as the measurement area (Figure $1 \mathrm{~A}$ and $1 \mathrm{C}$ ), which provided the maximum, minimum, SD, and mean elastic modulus in kilopascals. A mean elastic modulus for both shoulders was recorded for all participants in both positions.

Elastic modulus measurements were analyzed using opensource Digital Imaging and Communications in Medicine software OsiriX MD (version 7.0, 64 bit; https://www.osirix-viewer.com/ osirix/overview/; Pixmeo SARL, Geneva, Switzerland). All measurements were performed in triplicate, and an average value was used for statistical analysis.

The interclass correlation coefficient (ICC) was calculated to determine the intrarater and interrater reliability of measurements of the CHL elastic modulus, both in the neutral and $30^{\circ}$ external rotation positions. Results were classified as poor $(\mathrm{ICC}=.00-.20)$, fair $(\mathrm{ICC}=.20-.40)$, good $(\mathrm{ICC}=.40-.75)$, or excellent $(\mathrm{ICC}>$ .75). The SEM was calculated as SD $\times \sqrt{ } 1-\mathrm{ICC}$, where SD is the SD of all scores of the subjects. ${ }^{22}$ The SEM was used for calculating the minimal detectable change (MDC) and was calculated as SEM $\times 1.96 \times \sqrt{ } 2$ to construct a $95 \%$ confidence interval $(\mathrm{CI}) .^{22}$

The interobserver reliability of elastic modulus measurements in the CHL was excellent in both the neutral position (dominant: ICC = $.876 ; 95 \% \mathrm{CI}, .737-.934 ; \mathrm{SEM}=13.5 ; \mathrm{MDC}=37.4$ and nondominant: $\mathrm{ICC}=.865 ; 95 \% \mathrm{CI}, .713-.928 ; \mathrm{SEM}=15.5 ; \mathrm{MDC}=43)$ and $30^{\circ}$ external rotation position (dominant: $\mathrm{ICC}=.85 ; 95 \% \mathrm{CI}$, .559-.932; $\mathrm{SEM}=19.5 ; \mathrm{MDC}=54.1$ and nondominant: $\mathrm{ICC}=.877$; 95\% CI, .664-.942; SEM = 16.9; MDC = 46.8). The intraobserver reliability of the $\mathrm{CHL}$ elastic modulus measurements was excellent in both the neutral position (dominant: ICC $=.834 ; 95 \% \mathrm{CI}$, .773-.883; $\mathrm{SEM}=15.6 ; \mathrm{MDC}=43.2$ and nondominant: $\mathrm{ICC}=.807$; 95\% CI, .737-.863; SEM = 18.5; $\mathrm{MDC}=51.3$ ) and $30^{\circ}$ external rotation position (dominant: $\mathrm{ICC}=.773 ; 95 \% \mathrm{CI}, .694-.838$; $\mathrm{SEM}=24 ; \mathrm{MDC}=66.5$ and nondominant: $\mathrm{ICC}=.803 ; 95 \% \mathrm{CI}$, $.732-.860 ;$ SEM = 21.4; $\mathrm{MDC}=59.3$ ).

\section{Statistical Analysis}

The ROMs on the dominant and nondominant sides were compared using the paired $t$ test (eg, forward flexion, lateral elevation, external rotation, and $90^{\circ}$ abduction with external rotation) and Wilcoxon rank-sum test (hand behind the back motion, elastic modulus of the CHL). All continuous variables were tested for deviation from the normal distribution using Kolmogorov-Smirnov test. Correlations between continuous variables with or without normal distributions were analyzed using Spearman correlation coefficient. Data were expressed as mean (SD) (forward flexion, lateral elevation, external rotation, and $90^{\circ}$ abduction with external rotation) and medians and interquartile ranges (IQR; hand behind the back motion).

To achieve a power of $80 \%$, statistical significance of .05 level, and effect size of 0.8, adequate sample size for each group was calculated to be 17, utilizing SPSS (version 23.0; IBM Corp, Armonk, NY).

All statistical analyses were performed using the statistical software package SPSS (version 23.0; IBM Corp). A value of $P<.05$ was accepted as statistically significant. 


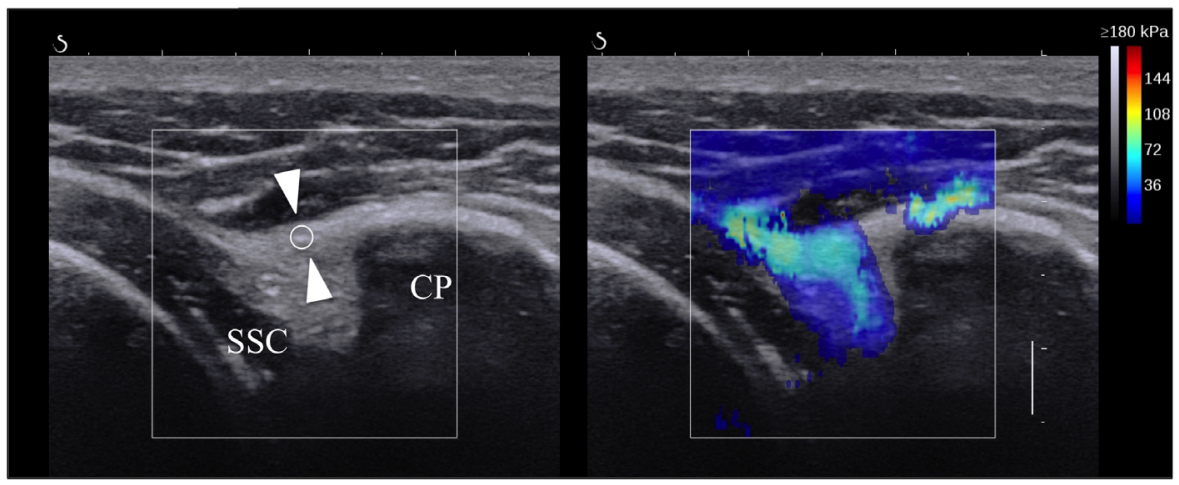

A

B

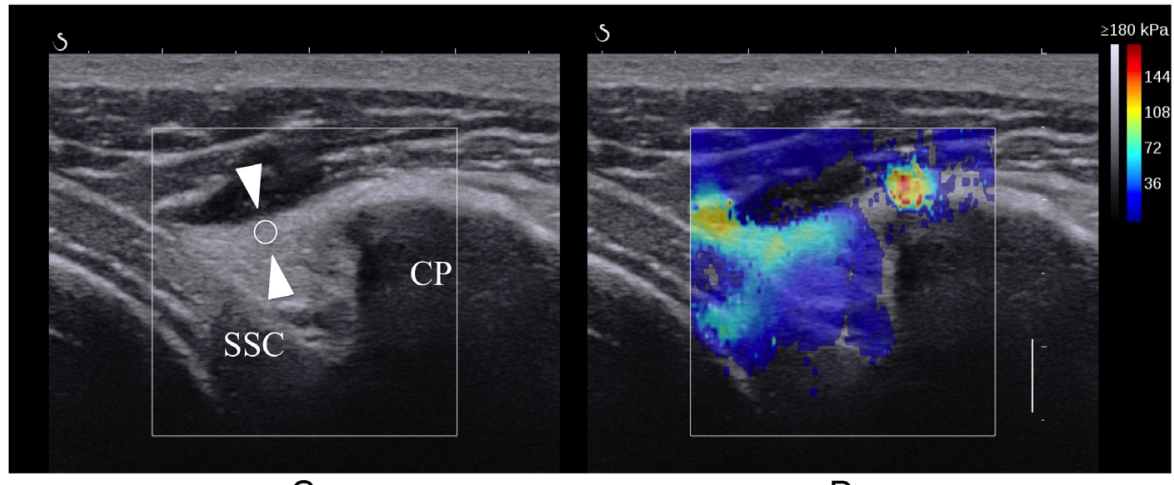

C

D

Figure 1 - Measurements of the elastic modulus of the coracohumeral ligament with shear-wave elastography in a 27-year-old man with shoulders placed in neutral (A and B) and ER positions (C and D). (A and C) Ultrasonographic images. (B and D) Elastographic images. Measurements are obtained at a central point within the coracoid process and attachment segment of the subscapularis (arrowheads) both in the neutral (A) and ER (C) positions. A circular target of interest with a diameter of $1.5 \mathrm{~mm}$ is set at the measurement point (white circle). The elastic modulus is $7.2 \mathrm{kPa}$ (B) in the neutral position and $32.2 \mathrm{kPa}$ (D) in the ER position. CP indicates coracoid process; ER, external rotation; SSC, subscapularis muscle.

\section{Ethical Approval}

The protocols of this study were approved by the institutional review board of the Iwate Prefectural Central Hospital (approval number: 2455). An informed consent was obtained from all study participants.

\section{Results}

Shoulder ROM comparisons between the dominant and nondominant sides are shown in Table 1 . The $90^{\circ}$ abduction with external rotation on the dominant side was significantly higher, but the hand behind the back motion was significantly lower on the dominant side than on the nondominant side (Table 1 and Supplementary Figure 1 [available online]).

Correlation coefficients between age and ROM for the dominant and nondominant sides are shown in Table 2. There were significant negative correlations between age and ROM (forward flexion, external rotation, and $90^{\circ}$ abduction with external rotation) on both the dominant and nondominant sides. There was a significant positive correlation between age and hand behind the back motion on the dominant side (Table 2).

Correlation coefficients between ROM and elasticity of the $\mathrm{CHL}$ in the neutral and $30^{\circ}$ external rotation positions on the dominant side are shown in Table 3. Significant negative correlations between the elastic modulus of the CHL and ROM were observed in forward flexion and external rotation in both the neutral
Table 1 Comparison of Shoulder ROM on the Domi-
nant and Nondominant Sides

\begin{tabular}{lccc}
\hline & \multicolumn{2}{c}{ Mean (SD) } & \\
\cline { 2 - 3 } Subjects & Dominant (84) & Nondominant (84) & $\boldsymbol{P}$ \\
\hline ROM, deg & & & \\
FF & $153(14)$ & $153(13)$ & .87 \\
LE & $133(21)$ & $135(19)$ & .16 \\
ER & $60(16)$ & $60(16)$ & .91 \\
ABER & $93(13)$ & $90(15)$ & $.01^{*}$ \\
HBB $^{\mathrm{a}}$ & T6 (T5-T8) & T5 (T4-T6) & $<.001^{* *}$ \\
\hline
\end{tabular}

Abbreviations: $\mathrm{ABER}, 90^{\circ}$ abduction with external rotation; ER, external rotation; FF, forward flexion; HBB, hand behind back; HF, horizontal flexion; LE, lateral elevation; ROM, range of motion; T4, fourth thoracic vertebrae; T5, fifth thoracic vertebrae; T6, sixth thoracic vertebrae; T7, seventh thoracic vertebrae; T8, eighth thoracic vertebrae.

${ }^{\mathrm{a}}$ Medians and interquartile ranges.

$* P<.05$. ** $P<.001$.

and $30^{\circ}$ external rotation positions, and $90^{\circ}$ abduction with external rotation in the $30^{\circ}$ external rotation position (Table 3). The elasticity of the $\mathrm{CHL}$ in the $30^{\circ}$ external rotation position showed a stronger correlation with ROM than that in the neutral position (Table 3).

Comparisons between elasticity of the CHL and age in both the neutral and $30^{\circ}$ external rotation positions on both the sides 
Table 2 Correlation Between Age and ROM on the Dominant and Nondominant Sides

\begin{tabular}{cccccc}
\hline & \multicolumn{2}{c}{ Dominant (84) } & & \multicolumn{2}{c}{ Nondominant (84) } \\
\cline { 2 - 3 } \cline { 5 - 6 } Subjects & $\boldsymbol{R}^{\mathbf{a}}$ & $\boldsymbol{P}$ & & $\boldsymbol{R}^{\mathbf{a}}$ & $\boldsymbol{P}$ \\
\hline Age/ROM & & & & \\
FF & -.44 & $<.001^{* *}$ & -.46 & $<.001^{* *}$ \\
LE & -.17 & .12 & -.2 & .07 \\
ER & -.52 & $<.001^{* *}$ & -.57 & $<.001^{* *}$ \\
ABER & -.41 & $<.001^{* *}$ & -.39 & $<.001^{* *}$ \\
HBB & .24 & $.03^{*}$ & .18 & .11 \\
\hline
\end{tabular}

Abbreviations: ABER, $90^{\circ}$ abduction with external rotation; ER, external rotation; FF, forward flexion; HBB, hand behind back; LE, lateral elevation; ROM, range of motion.

${ }^{\text {a }}$ Spearman correlation coefficient.

$* P<.05 . * * P<.001$

Table 3 Correlation Between ROM and Elasticity of the $\mathrm{CHL}$ in Neutral and ER Positions on the Dominant Side

\begin{tabular}{cccccc}
\hline & FF & LE & ER & ABER & HBB \\
\hline \multicolumn{7}{l}{ ROM/CHL elastic modulus } \\
Neutral \\
$R^{\mathrm{a}}$ & -.22 & -.07 & -.26 & -.17 & .03 \\
$P$ & $.046^{*}$ & .56 & $.02^{*}$ & .12 & .76 \\
$\mathrm{ER}$ at $30^{\circ}$ & & & & & \\
$R^{\mathrm{a}}$ & -.35 & -.1 & -.46 & -.53 & .14 \\
$P$ & $.001^{* *}$ & .37 & $<.001^{* * *}$ & $<.001^{* * *}$ & .19 \\
\hline
\end{tabular}

Abbreviations: ABER, $90^{\circ}$ abduction with external rotation; $\mathrm{CHL}$, coracohumeral ligament; ER, external rotation; FF, forward flexion; HBB, hand behind back; LE, lateral elevation; ROM, range of motion.

${ }^{\text {a }}$ Spearman correlation coefficient.

$* P<.05$. $* * P<.01$. *** $P<.001$.

Table 4 Elasticity of the CHL in Neutral and ER Positions According to Age Group

\begin{tabular}{|c|c|c|c|c|}
\hline \multirow[b]{3}{*}{ Subjects } & \multicolumn{4}{|c|}{$\mathrm{CHL}$ elastic modulus ${ }^{\mathrm{a}}, \mathrm{kPa}$} \\
\hline & $\begin{array}{l}\text { Younger } \\
(20-39 \text { y) }\end{array}$ & $\begin{array}{l}\text { Middle } \\
(40-59 \text { y) }\end{array}$ & $\begin{array}{l}\text { Older } \\
(\geq 60 \mathrm{y})\end{array}$ & \\
\hline & $(n=36)$ & $(n=33)$ & $(n=15)$ & $P$ value \\
\hline \multicolumn{5}{|l|}{ Dominant } \\
\hline Neutral & $56.6(31.7)$ & $83.2(41.1)$ & $78.4(37.1)$ & $.01 *$ \\
\hline $\mathrm{ER}$ at $30^{\circ}$ & $71.4(32.2)$ & $110.8(45.3)$ & $135.5(63.5)$ & $<.001 * *$ \\
\hline \multicolumn{5}{|l|}{ Nondominant } \\
\hline Neutral & $58.9(36.8)$ & $82.2(43.2)$ & $89.9(43.5)$ & $.02 *$ \\
\hline $\mathrm{ER}$ at $30^{\circ}$ & $85.9(41.8)$ & $114(48.3)$ & $124(50.4)$ & $.01 *$ \\
\hline
\end{tabular}

Abbreviations: CHL, coracohumeral ligament; ER, external rotation. ${ }^{\text {aV Values are }}$ represented as mean $(\mathrm{SD})$.

$* P<.05$. $* * P<.001$.

are shown in Table 4. The elastic modulus of the CHL in the middle and older age groups was significantly higher than that in the younger groups in both the neutral and $30^{\circ}$ external rotation positions, regardless of the side of dominance (Table 4, Figure 2, and Supplementary Figure 2 [available online]).
Correlation coefficients according to age groups between ROM and elasticity of the CHL in the 2 positions are shown in Table 5. In the younger age group, a negative correlation was observed between the elastic modulus of the CHL in the neutral position and external rotation. In the middle age group, a negative correlation was observed between the elastic modulus of the CHL in the $90^{\circ}$ abduction with external rotation of $30^{\circ}$ external rotation positions. In the older age group, there were significant negative correlations between the elastic modulus in the $30^{\circ}$ external rotation and $90^{\circ}$ abduction with external rotation positions (Table 5). These changes were similar on the nondominant side (Supplementary Table 1 [available online]).

\section{Discussion}

The most important findings of this study were that the elastic modulus of the CHL was negatively correlated with forward flexion, external rotation in the neutral position, and $90^{\circ}$ abduction with external rotation in the $30^{\circ}$ external rotation position. Furthermore, the elastic modulus tended to increase with age, irrespective of the side of dominance, and measuring it in the $30^{\circ}$ external rotation position was more closely associated with ROM restriction in $90^{\circ}$ abduction with external rotation (aged $>40 \mathrm{y}$ ) and in external rotation (aged $>60 \mathrm{y}$ ).

The CHL attaches to the horizontal limb of the coracoid process and covers the rotator interval, ${ }^{23}$ extending to envelop the entire supraspinatus, infraspinatus, and subscapularis muscles and their insertions. ${ }^{4}$ The CHL is composed of irregular and sparse fibers with an abundance of type III collagen, has no boundary with the superior glenohumeral ligament, and provides ligament flexibility. 4,24

A recent study using magnetic resonance arthrography revealed that both thickening of the CHL or obliteration of the subcoracoid fat triangle correlated with ROM restrictions in forward flexion, external rotation, and hand behind back motion, and the degree of restriction increased with age in patients with anterior glenohumeral instability. ${ }^{25}$ However, the measurement site when using magnetic resonance arthrography focuses on the sagittal plane of the CHL overlay on the supraspinatus, ${ }^{25}$ and visualization of the CHL fibers at the surface of the subscapularis is difficult. The advantage of shear-wave elastography is that it can evaluate the CHL fibers at the surface of the subscapularis.

One study reported that shear-wave elastography showed that the surface of the CHL in the subscapularis on the affected side was thicker and stiffer in patients with frozen shoulder than that on the unaffected side. ${ }^{21}$ However, there was no significant difference between the affected and healthy shoulders in maximal external rotation..$^{21}$ In the present study, the elastic modulus of the CHL in healthy participants was less than that reported previously. ${ }^{21}$ This could be explained by the use of different equipment, measurements, and analyses in each study. A measurement area taken closer to the muscle attachment site might result in higher measurement values of the CHL elastic modulus, which may be more consistent with the previous report. ${ }^{21}$ Arm position has a significant influence on the relative elasticity of the CHL with the arm in the external rotation position. When the shoulder position is changed from the neutral to the external rotation position, the CHL tightens and its elastic modulus increases until maximum physiological limitation is reached. The elastic modulus values were greater, and its correlation coefficient also tended to be larger than those in the neutral position in this study. We chose to use an external rotation with an angle of $30^{\circ}$, which is half of the normal angle of external 


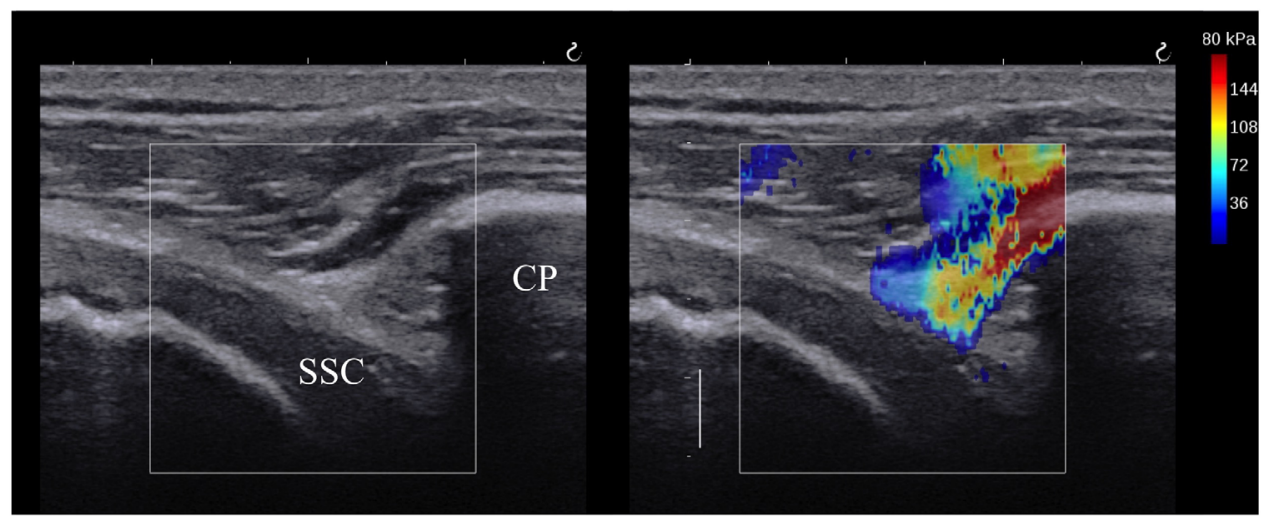

A

B

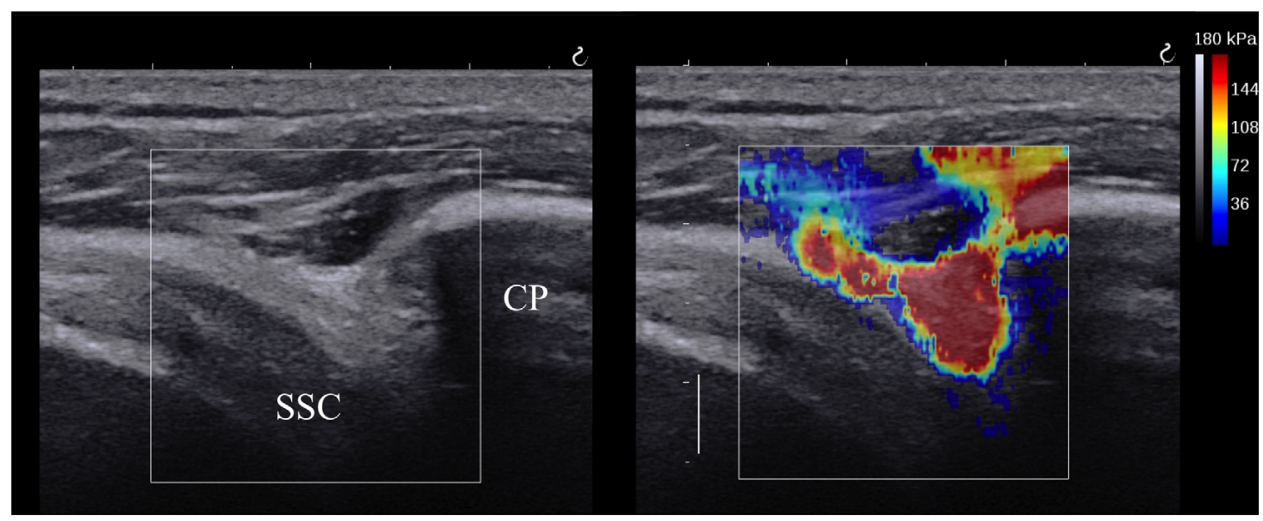

C

D

Figure 2 - Elastic modulus of the CHL with shear-wave elastography in a 63-year-old man with shoulders placed in neutral (A and B) and ER positions (C and D). (A and C) Ultrasonographic images. (B and D) Elastographic images. Elastic modulus in the CHL in the older group is higher (red in online article) than that in the younger groups. Elastic modulus in the entire CHL in the ER position (D) is higher (red in online article) than that in the neutral position (A); elastic modulus: 110 and $201 \mathrm{kPa}$, respectively. Red (in online article) pixels indicate a higher modulus and blue (in online article) pixels indicate a lower modulus. CHL indicates coracohumeral ligament; CP, coracoid process; SSC, subscapularis muscle.

Table 5 Correlation Between ROM and Elasticity of the CHL in Neutral and ER Positions on the Dominant Side According to Age Group

\begin{tabular}{|c|c|c|c|c|c|c|c|}
\hline Age & CHL elastic modulus & & FF & LE & ER & ABER & HBB \\
\hline \multirow{4}{*}{$\begin{array}{l}\text { Younger }(20-39 y) \\
(\mathrm{n}=36)\end{array}$} & \multirow[t]{2}{*}{ Neutral } & $R$ & -.12 & .12 & -.33 & .29 & .01 \\
\hline & & $P$ & .48 & .47 & $.047 *$ & .09 & .98 \\
\hline & \multirow[t]{2}{*}{$\mathrm{ER}$ at $30^{\circ}$} & $R$ & -.05 & .24 & -.30 & .24 & .05 \\
\hline & & $P$ & .78 & .15 & .08 & .17 & .75 \\
\hline \multirow{4}{*}{$\begin{array}{l}\text { Middle }(40-59 y) \\
(n=33)\end{array}$} & \multirow[t]{2}{*}{ Neutral } & $R$ & -.09 & -.28 & -.04 & -.34 & .02 \\
\hline & & $P$ & .60 & .11 & .85 & .05 & .91 \\
\hline & \multirow[t]{2}{*}{ ER at $30^{\circ}$} & $R$ & -.24 & -.21 & -.19 & -.62 & .25 \\
\hline & & $P$ & .17 & .23 & .29 & $<.001 * * *$ & .17 \\
\hline \multirow{4}{*}{$\begin{array}{l}\operatorname{Older}(\geq 60 y) \\
(n=15)\end{array}$} & \multirow[t]{2}{*}{ Neutral } & $R$ & -.36 & -.16 & -.35 & -.25 & .14 \\
\hline & & $P$ & .19 & .58 & .20 & .38 & .62 \\
\hline & \multirow[t]{2}{*}{$\mathrm{ER}$ at $30^{\circ}$} & $R$ & -.44 & -.16 & -.59 & -.71 & .23 \\
\hline & & $P$ & .10 & .57 & $.02 *$ & $.003 * *$ & .41 \\
\hline
\end{tabular}

Abbreviations: $\mathrm{ABER}, 90^{\circ}$ abduction with external rotation; $\mathrm{CHL}$, coracohumeral ligament; ER, external rotation; FF, forward flexion; HBB, hand behind back; LE, lateral elevation; ROM, range of motion.

$* P<.05$. $* * P<.01 . * * * P<.001$. 
rotation. For evaluating elastic changes of the $\mathrm{CHL}$, measuring the elastic modulus of the $\mathrm{CHL}$ in the $30^{\circ}$ external rotation position is more appropriate than doing so in the neutral position.

Measuring ROM and understanding its changes with age are important for evaluation of shoulder impairments. ${ }^{26}$ Although a number of reports have provided estimates of normal ROMs for the shoulder, ${ }^{12,27,28}$ shoulder ROM decreases with age in a normal population. ${ }^{12,26}$ However, there are no reported standards for ROM restriction regarding dominant side, age, posture, muscle tightness, and capsular stiffness. In this study, $90^{\circ}$ abduction with external rotation on the dominant side was greater, and hand behind the back motion on the dominant side was less than those on the nondominant side. Furthermore, the ROM decreased during forward flexion, external rotation, and $90^{\circ}$ abduction with external rotation on both sides, and hand behind the back motion on the dominant side was associated with age, as previously reported. ${ }^{12}$ Microtrauma, humeral retroversion, and posterior capsular tightness are common on the dominant side, which could explain the changes in glenohumeral adaptations with age. ${ }^{29}$

There is currently no data available regarding the association among elasticity of the CHL, ROM, and age in healthy adult individuals. We measured the $\mathrm{CHL}$ at the anterior surface of the subscapularis and demonstrated that the elasticity was directly related to age, as well as to forward flexion, external rotation, and $90^{\circ}$ abduction with external rotation. Anterior fibers of the CHL play an important role in the smooth movement of the subscapularis muscle. We observed significant negative correlations of $\mathrm{CHL}$ elasticity with external rotation at a $30^{\circ}$ position of external rotation and $90^{\circ}$ abduction with external rotation in participants older than 60 years, and with $90^{\circ}$ abduction with external rotation on the dominant side in participants aged 40-59 years, in contrast to the nondominant side. This study indicated that elasticity of the CHL was directly involved in ROM restriction on the dominant side of middle-aged and elderly individuals. However, similar results were obtained in the neutral position in the 20- to 39-year-old participants, who had a larger ROM. This could be explained by joint laxity related to muscle or other joints, except for the glenohumeral joint, such as the scapulothoracic joint, rib, and spine motion. We measured elasticity in the supine position, and the humeral head moved downward against the glenoid fossa, which could have led to an increase in tension of the $\mathrm{CHL}$ in the younger age group. Although there were no significant negative correlations of the elastic modulus of the CHL with forward flexion, lateral elevation, and hand behind the back motion, correlations between elastic modulus of the CHL and forward flexion increased with age. During forward flexion, the humeral head externally rotates with the sliding of the subscapularis against the glenoid fossa, which could explain the negative correlations between age and ROM, regardless of the side of dominance.

The limitations of this study were as follows: (1) No clinical, arthroscopic, or histological evaluation was performed. (2) A small number of subjects were included, especially in the older group. (3) We did not exclude degenerative joint disease with imaging. (4) Patients with tendinopathy, calcific tendinitis, and intratendinous rotator cuff tears were not excluded because these were difficult to identify with ultrasound evaluations. (5) Only a specific region of interest of the CHL near the coracoid process was measured. (6) Evaluation of the elasticity in a supine position is different from ROM evaluation in a standing position. (7) Differences in bone morphology and elasticity of soft tissues other than CHL might affect ROM. (8) Muscular effects on ROM were not evaluated.

No previous study has assessed the association among elasticity of the CHL, ROM, and age in healthy adult participants.
We show that age-related CHL stiffening induced ROM restrictions. Shear-wave elastography allows evaluation and diagnosis of the condition of shoulder disorders, compared with healthy subjects, by a simple examination at the body surface. In addition, with the decreasing elasticity of the CHL due to age, releasing the CHL could represent an option to regain shoulder ROM. Further studies are needed to evaluate the relationships between pathological changes of aging and elasticity of the CHL.

\section{Conclusions}

Elastic modulus of the CHL negatively correlated with forward flexion, external rotation in a neutral position, and $90^{\circ}$ abduction with external rotation in the $30^{\circ}$ external rotation position, and tended to increase with age irrespective of the side of dominance. Using shear-wave elastography, evaluation of the elasticity in the $30^{\circ}$ external rotation position is more specific for measuring ROM restriction in $90^{\circ}$ abduction with external rotation and external rotation and better reflects the pathological changes of the CHL.

\section{Acknowledgments}

This research did not receive any specific grant from funding agencies in the public, commercial, or not-for-profit sectors. The authors declare that they have no conflict of interest. All procedures performed in studies involving human participants were in accordance with the ethical standards of the Iwate Prefectural Central Hospital and/or national research committee and with the 1964 Declaration of Helsinki and its later amendments or comparable ethical standards. Informed consent was obtained from all individual participants included in the study.

\section{References}

1. McClure PW, Michener LA, Sennett BJ, Karduna AR. Direct 3dimensional measurement of scapular kinematics during dynamic movements in vivo. J Shoulder Elbow Surg. 2001;10:269-277. PubMed ID: 11408911 doi:10.1067/mse.2001.112954

2. Ludewig PM, Phadke V, Braman JP, Hassett DR, Cieminski CJ, LaPrade RF. Motion of the shoulder complex during multiplanar humeral elevation. J Bone Joint Surg Am. 2009;91:378-389. PubMed ID: 19181982 doi:10.2106/JBJS.G.01483

3. Edmondston SJ, Aggerholm M, Elfving S, et al. Influence of posture on the range of axial rotation and coupled lateral flexion of the thoracic spine. J Manipulative Physiol Ther. 2007;30:193-199. PubMed ID: 17416273 doi:10.1016/j.jmpt.2007.01.010

4. Arai R, Nimura A, Yamaguchi $K$, et al. The anatomy of the coracohumeral ligament and its relation to the subscapularis muscle. J Shoulder Elbow Surg. 2014;23:1575-1581. PubMed ID: 24766789 doi:10.1016/j.jse.2014.02.009

5. Depalma AF. Loss of scapulohumeral motion (frozen shoulder). Ann Surgery. 1952;135:193-204. doi:10.1097/00000658-195202000-00005

6. Edelson JG, Taitz C, Grishkan A. The coracohumeral ligament. Anatomy of a substantial but neglected structure. J Bone Joint Surg Br. 1991;73:150-153. PubMed ID: 1991752 doi:10.1302/ 0301-620X.73B1.1991752

7. Ozaki J, Nakagawa Y, Sakurai G, Tamai S. Recalcitrant chronic adhesive capsulitis of the shoulder. Role of contracture of the coracohumeral ligament and rotator interval in pathogenesis and treatment. J Bone Joint Surg Am. 1989;71:1511-1515. PubMed ID: 2592391 doi:10.2106/00004623-198971100-00009 
8. Neer CS 2nd, Satterlee CC, Dalsey RM, Flatow EL. The anatomy and potential effects of contracture of the coracohumeral ligament. Clin Orthop Relat Res. 1992;(280):182-185.

9. Lee SY, Park J, Song SW. Correlation of MR arthrographic findings and range of shoulder motions in patients with frozen shoulder. Am J Roentgenol. 2012;198:173-179. PubMed ID: 22194494 doi:10.2214/ AJR.10.6173

10. Hagiwara Y, Sekiguchi T, Ando A, et al. Effects of arthroscopic coracohumeral ligament release on range of motion for patients with frozen shoulder. Open Orthop J. 2018;12:373-379. PubMed ID: 30288192 doi:10.2174/1874325001812010373

11. Park JH, Yang SH, Rhee SM, Oh JH. The effect of concomitant coracohumeral ligament release in arthroscopic rotator cuff repair to prevent postoperative stiffness: a retrospective comparative study. Knee Surg Sports Traumatol Arthrosc. 2019;27(12):3881-3889. PubMed ID: 30850882 doi:10.1007/s00167-019-05433-2

12. Barnes CJ, Van Steyn SJ, Fischer RA. The effects of age, sex, and shoulder dominance on range of motion of the shoulder. J Shoulder Elbow Surg. 2001;10:242-246. PubMed ID: 11408905 doi:10.1067/ mse.2001.115270

13. Boone DC, Azen SP. Normal range of motion of joints in male subjects. J Bone Joint Surg Am. 1979;61:756-759. PubMed ID: 457719 doi:10.2106/00004623-197961050-00017

14. Hagiwara Y, Kanazawa K, Ando A, et al. Blood flow changes of the anterior humeral circumflex artery decrease with the scapula in internal rotation. Knee Surg Sports Traumatol Arthrosc. 2015;23:1467-1472. PubMed ID: 24390057 doi:10.1007/s00167-013-2823-2

15. Yabe Y, Hagiwara Y, Suda H, et al. Joint immobilization induced hypoxic and inflammatory conditions in rat knee joints. Connect Tissue Res. 2013;54:210-217. PubMed ID: 23496380 doi:10.3109/ 03008207.2013.786056

16. Hagiwara Y, Ando A, Onoda Y, et al. Coexistence of fibrotic and chondrogenic process in the capsule of idiopathic frozen shoulders. Osteoarthritis Cartilage. 2012;20:241-249. PubMed ID: 22233812 doi:10.1016/j.joca.2011.12.008

17. Bercoff J, Tanter M, Fink M. Supersonic shear imaging: a new technique for soft tissue elasticity mapping. IEEE Trans Ultrason Ferroelectr Freq Control. 2004;51:396-409. PubMed ID: 15139541 doi:10.1109/TUFFC.2004.1295425

18. Shiina T, Nightingale KR, Palmeri ML, et al. WFUMB guidelines and recommendations for clinical use of ultrasound elastography: part 1: basic principles and terminology. Ultrasound Med Biol. 2015;41: 1126-1147. PubMed ID: 25805059 doi:10.1016/j.ultrasmedbio. 2015.03.009
19. De Zordo T, Chhem R, Smekal V, et al. Real-time sonoelastography: findings in patients with symptomatic Achilles tendons and comparison to healthy volunteers. Ultraschall Med. 2010;31:394-400. PubMed ID: 19946833 doi:10.1055/s-0028-1109809

20. Rosskopf AB, Ehrmann C, Buck FM, Gerber C, Fluck M, Pfirrmann $\mathrm{CW}$. Quantitative shear-wave us elastography of the supraspinatus muscle: reliability of the method and relation to tendon integrity and muscle quality. Radiology. 2016;278:465-474. PubMed ID: 26540450 doi:10.1148/radiol.2015150908

21. Wu CH, Chen WS, Wang TG. Elasticity of the coracohumeral ligament in patients with adhesive capsulitis of the shoulder. Radiology. 2016;278:458-464. PubMed ID: 26323030 doi:10.1148/radiol. 2015150888

22. Weir JP. Quantifying test-retest reliability using the intraclass correlation coefficient and the SEM. J Strength Cond Res. 2005;19: 231-240. PubMed ID: 15705040

23. Harryman DT, Sidles JA, Harris SL, Matsen FA. The role of the rotator interval capsule in passive motion and stability of the shoulder. J Bone Joint Surg Am. 1992;74:53-66. PubMed ID: 1734014 doi:10. 2106/00004623-199274010-00008

24. Arai R, Mochizuki T, Yamaguchi K, et al. Functional anatomy of the superior glenohumeral and coracohumeral ligaments and the subscapularis tendon in view of stabilization of the long head of the biceps tendon. J Shoulder Elbow Surg. 2010;19:58-64. PubMed ID: 19535271 doi:10.1016/j.jse.2009.04.001

25. Kanazawa K, Hagiwara Y, Kawai N, et al. Correlations of coracohumeral ligament and range of motion restriction in patients with recurrent anterior glenohumeral instability evaluated by magnetic resonance arthrography. J Shoulder Elbow Surg. 2017;26:233-240. PubMed ID: 27814944 doi:10.1016/j.jse.2016.09.016

26. Clarke GR, Willis LA, Fish WW, Nichols PJ. Preliminary studies in measuring range of motion in normal and painful stiff shoulders. Rheumatol Rehabil. 1975;14:39-46. PubMed ID: 1121637 doi:10. 1093/rheumatology/14.1.39

27. Ahlberg A, Moussa M, Al-Nahdi M. On geographical variations in the normal range of joint motion. Clin Orthop Relat Res. 1988; 234:229-231.

28. Poppen NK, Walker PS. Normal and abnormal motion of the shoulder. J Bone Joint Surg Am. 1976;58:195-201. PubMed ID: 1254624 doi:10.2106/00004623-197658020-00006

29. Thomas SJ, Swanik CB, Kaminski TW, et al. Humeral retroversion and its association with posterior capsule thickness in collegiate baseball players. J Shoulder Elbow Surg. 2012;21:910-916. PubMed ID: 21856177 doi:10.1016/j.jse.2011.05.028 